\title{
El movimiento obrero en Chile: De la Unidad Popular a la CONCERTACIÓN
}

\author{
Paul W. Drake \\ Universidad de California, San Diego, Estados Unidos
}

\begin{abstract}
Resumen
Este artículo ofrece la historia del debilitamiento del movimiento obrero en Chile en los últimos treinta años, en su rol económico, en su posición institucional, y en su poder político. Examina su trayectoria antes, durante, y después del gobierno militar de Augusto Pinochet. Analiza sus dificultades actuales estableciendo una comparación con la realidad similar por la que atraviesan muchos otros países. Pregunta si el golpe de 1973 fue la causa necesaria para generar la condición negativa que vive hoy el sindicalismo. Tras el análisis, concluye que el factor más importante para explicar los problemas actuales de los sindicatos es la evolución económica y por eso el futuro del movimiento de los trabajadores no parece auspicioso en este momento.
\end{abstract}

\begin{abstract}
This article offers a history during the last thirty years of the weakening of the labor movement in Chile, in its economic role, its institutional position, and its political power. This study examines that movement's trajectory before, during, and after the military government of Augusto Pinochet. This essay analyzes its current difficulties in comparison with the similar situation in many other countries. The question is asked whether the military coup of 1973 was necessary to create the negative condition of trade unionism today. The conclusion is that the evolution of the economy is the most important factor that explains the existing problems of unions. Consequently, the future of the workers' movement does not appear auspicious in this moment.
\end{abstract}

PALABRAS CLAVE • Chile • Movimiento Obrero • Sindicalismo • Allende • Pinochet • Concertación - Neoliberalismo

Durante los últimos trienta años en Chile, la trayectoria del movimiento obrero ha sido influenciada por tres factores principales: el contexto económico, el contexto institucional y el contexto político. Estos fueron drásticamente transformados por el golpe militar del 11 de septiembre de 1973. La situación actual de los trabajadores y sus sindicatos refleja la herencia anterior al régimen de Pinochet, las transformaciones profundas que ocurrieron bajo ese autoritarismo, y la evolución experimentada desde el retorno de la democracia con la llegada de la Concertación en 1990. En el fondo, es la historia del debilitamiento del movimiento laboral en su rol económico, en su posición institucional y en su poder político. Ello, en contraste al amplio terreno alcanzado por los empresarios ${ }^{1}$. 
Antes del pronunciamiento militar, los trabajadores lucharon dentro de una economía protegida por el Estado de compromiso, donde existía una fuerza institucional amplia e imperaba un sistema legal con derechos que, aunque restringidos, eran significativos y estaban incorporados en el código de 1924-31. Se trataba de una democracia dominada por tres partidos políticos grandes y que dedicaban gran parte de su trabajo a muchos de los programas elaborados por los sindicatos: el Comunista, el Socialista y el Demócrata Cristiano. Durante la tiranía de Augusto Pinochet (1973-90), en cambio, sufrieron de una economía abierta al mercado doméstico e internacional. Padecieron los efectos de un nuevo reglamento laboral (1979-81), el que contemplaba restricciones severas sobre sus organizaciones y acciones. Era una dictadura represiva, sin la participación de sus compañeros políticos. Sólo al restaurarse la democracia gozaron de más justicia social, pero ello aún en una economía neoliberal y globalizada. Así, y si bien todavía no ocurría un restablecimiento de las leyes fundamentales que reinaban hasta 1973 y les faltaba recuperar su capacidad organizacional, lograron, nuevamente, algunas regulaciones favorables en el ámbito legal. En esa realidad, el sindicalismo actuó con mucha más libertad, pero con partidos políticos menos capaces o dispuestos a defender sus causas.

Aunque con la Concertación su posición mejoró, el mal momento por el que atraviesa actualmente deriva todavía básicamente de sus derrotas bajo Augusto Pinochet. Dadas las conquistas modestas de los trabajadores organizados a pesar de la redemocratización, y de las dificultades similares de los sindicalistas en muchos otros países hoy día, se puede concluir que los factores más importantes a través de estos treinta años han sido los cambios económicos. Debido a la improbabilidad actual de una ruptura en los contextos económicos, institucionales y políticos, el futuro del movimiento obrero no parece muy positivo, por lo menos en el corto plazo.

\section{ANTES DEL GOBIERNO MILITAR}

Desde la década de 1930 hasta 1970, el movimiento obrero y sus partidos políticos crecieron dentro de un modelo económico de industrialización protegida. En 1970, el porcentaje de la población activa en sindicatos llegó a casi un tercio. Tenían derechos y organizaciones importantes, representadas por la Central Única de Trabajadores (CUT). Después de los partidos políticos, los sindicatos fueron el portavoz más fuerte del pueblo. Sin embargo, por razón a las limitaciones de sus instituciones y de sus poderes legales, los trabajadores tenían menos fuerza con los empleadores que con el Estado. Por eso, dependían de sus partidos políticos, especialmente los comunistas y socialistas, para atraer el apoyo del gobierno para obtener mejores remuneraciones, condiciones de trabajo y concesiones del sector privado. Esa ayuda del gobierno nacional era sumamente crucial para combatir la inflación crónica. Esa colaboración con el Estado culminó con la Unidad Popular (1970-73), cuando los trabajadores conquistaron más que nunca. Fue el gobierno izquierdista más revolucionario en la historia de la América del Sur.

Durante la Unidad Popular, los amigos principales del movimiento obrero fueron los marxistas en el partido Socialista y en el Comunista. Muchos de los sindicatos compartieron con esas agrupaciones políticas una visión ideológica de una transición rápida al socialismo. Los sindicalistas avanzaron, simultáneamente, en una agenda práctica de mejoramiento de las condiciones de los 
trabajadores y otra ideológica de la transformación nacional anti-capitalista. Ambas fueron borradas por el golpe militar de $1973^{2}$.

\section{BAJ O EL GOBIERNO MILITAR}

Con el derrocamiento de Presidente Salvador Allende (1970-73), las Fuerzas Armadas atacaron los sindicatos y, aun más, los partidos de izquierda se convirtieron en sus enemigos mayores. Por razón de esa represión feroz, el movimiento obrero se retiró desde 1973 a 1976, y después gradualmente comenzó a recomponerse entre 1976 y 1979. Entre 1979 y 1981, algunos trabajadores trataron de negociar con cuidado con las empresas, pero tuvieron que retrodecer de nuevo durante la depresión de 1981-83. Movilizaron las protestas contra la dictadura entre 1983 y 1986, y más tarde participaron en la campaña para la redemocratización durante 1986-90, encabezada por los partidos políticos ${ }^{3}$.

Tras la destrucción de la Unidad Popular, el régimen autoritario paralizó al sindicalismo con un nuevo modelo económico. De vez en cuando, los programas de los Chicago Boys ayudaron a algunos trabajadores, por ejemplo, con la estabilización de los precios, pero casi siempre dañaron la capacidad sindical. Primero, la dictadura sofocó la inflación, la cual había sido antes la causa de muchas movilizaciones y demandas sindicales. Segundo, aumentó el desempleo y el subempleo, creando obstáculos para sindicatos con la misión de intervenir en el mercado laboral. Tercero, redujo el tamaño relativo de los sectores manufactureros, constructores, mineros, estatales, es decir, las fortalezas tradicionales del movimiento sindical. Al mismo tiempo, la expansión del sector de servicios y del sector informal impidió el alcance de los sindicatos. Cuarto, cortó los servicios sociales para los trabajadores. Quinto, reprimió los salarios. A la vez, la redistribución del ingreso desde los trabajadores hacia la clase alta y media socavó la clase baja. Sexto, la privatización tuvo un impacto mixto sobre los trabajadores. Algunos en el sector público se empeoraron, pero algunos en las industrias privatizadas prosperaron. En ambos casos, normalmente las privatizaciones perjudicaron los sindicatos. Finalmente, la abertura de la economía a las corrientes internacionales aumentó la presión sobre los trabajadores, su empleo, su seguridad, su productividad, sus salarios, sus beneficios y, además, sus demandas y sus sindicatos. En general, se deterioró la remuneración, la estabilidad, la calidad y las condiciones de trabajo. Para sobrevivir, los trabajadores tuvieron que llegar a ser más flexibles, individuales y silenciosos. No pudieron dedicarse fácilmente a los sindicatos, a las negociaciones colectivas o a las luchas de clase.

Después de estos cambios neoliberales, la crisis de la deuda y la depresión de 1981-85 exacerbaron las condiciones desfavorables para los trabajadores, especialmente el desempleo, el empleo precario y el ingreso inadecuado. Entonces, la situación de los obreros mejoró durante la recuperación entre 1986 y 1989, particularmente el empleo y el salario real. Sin embargo, la clase obrera salió de la dictadura mucho más deteriorada que antes, notablemente en las facetas más pertinentes para la sindicalización.

Para la situación antes del golpe, unos estudios muy útiles incluyen Angell (1972) y Winn (1986).

Para la historia laboral bajo Pinochet, los textos básicos son Campero y Valenzuela (1981); Gallitelli y Thompson (1982);

Ruiz-Tagle (1985); Barrera, et al. (1985); Frías (1989); Barrera y Falabella (1990); y Piñera (1990). 
Como las transformaciones económicas, los cambios institucionales bajo Pinochet también sometieron al movimiento obrero a la atomización. Las dos reformas dejaron a los trabajadores dominados por el mercado. Los sindicatos llegaron a ser muy reducidos en su capacidad de presionar a los empresarios 0 al Estado. En primer lugar, los militares sacaron a los sindicalistas más radicales. En segundo término, eliminaron las confederaciones y federaciones nacionales, los derechos básicos de asociación y acción sindical, y las actividades políticas. Por último, consolidaron las nuevas reglas en el Plan Laboral de 1979-81.

El Plan extendió el modelo neoliberal desde la esfera económica hasta el mundo legal de los sindicatos. Reconoció la legalidad de sindicalismo, pero permitió solamente actividades restringidas en la empresa local. Limitó estrictamente el poder y el control de los sindicatos sobre sus líderes, miembros y puestos, restringiendo sus negociaciones colectivas y sus huelgas. Dio mucha libertad a los empleadores para contratar, despedir y reemplazar a los trabajadores, para disciplinarlos y para determinar sus condiciones de trabajo, como la jornada. En efecto, prohibió la negociación colectiva para muchos trabajadores, especialmente a los con trabajo temporal o en empresas pequeñas, públicas o vinculadas a la agricultura. Redujo el rol gubernamental en disputas laborales y en servicios sociales. El resultado del plan fue la institucionalización de un sindicalismo muy frágil y fragmentado.

Aunque los sindicatos condenaron estas leyes, las usaron para reanimar sus actividades. Recrearon algunas de sus organizaciones, eligieron nuevos líderes, negociaron con algunas empresas, movilizaron huelgas y manifestaron su descontento con su trato, particularmente, el desempleo y la inseguridad de trabajo. Además, refortalecieron sus vínculos con los partidos políticos de la oposición: la Democracia Cristiana, el Socialista y el Comunista. Recibieron apoyo de ellos, de la Iglesia Católica y de unos sindicatos internacionales en los Estados Unidos y Europa. La movilización sindical aumentó durante 1979-81, disminuyó durante la recesión de 1982-85, y surgió de nuevo a través de los últimos años de la dictadura y el comienzo de la democracia. Los sindicalistas participaron masivamente en las protestas de 1983-85 y en la campaña de redemocratizacion en 1986-89, dominada por los partidos políticos. Reestablecieron su confederación nacional, la Central Unitaria de Trabajadores (CUT), en 1988.

A pesar de los avances en el segundo quinquenio de los ochenta, los sindicatos al fin del régimen autoritario solamente representaron al $11 \%$ de la fuerza de trabajo, menos que la mitad del porcentaje bajo Allende. Además, los sindicatos llegaron a ser más pequeños, cayendo desde un promedio de miembros en cada sindicato de 140 en 1972 a 71 en 1989. Sin embargo, mantuvieron apoyo público; en una encuesta en 1986, el 57 \% de los chilenos expresó una opinión positiva de los sindicatos.

A fines de esa década tres tendencias dominaron la clase obrera. Una minoría pequeña parecía como el movimiento antes de Pinochet. Perteneció a sindicatos militantes y politizados, con lazos con la confederación nacional y con los partidos políticos de la oposición, y concentrados en los sectores tradicionales del sindicalismo fuerte. Ellos manifestaron sus demandas económicas y políticas a los niveles locales y nacionales. Sin embargo, quedaron más independientes de las organizaciones nacionales y políticas que antes de Pinochet. También se expresaron posiciones menos ideológicas y radicales que antes. Aunque muchos se identificaron todavía con los comunistas y socialistas, más sindicalistas ahora inclinaron hacia los demócrata cristianos. Una segun- 
da minoría más pequeña de trabajadores se afilió con sindicatos apolíticos. Identificados con sectores nuevos y más modernos, actuaron principalmente al nivel de la empresa. La gran mayoría de los asalariados existía fuera de los sindicatos, como individuos en el mercado, sin muchas conexiones con los partidos políticos.

En el crepúsculo de la dictadura, los partidos políticos históricamente asociados con el movimiento obrero no le suministraron tanta ayuda como en el pasado. En la Concertación, los demócrata cristianos y los socialistas (tanto en el Partido Socialista como en el Partido por la Democracia) querían evitar actividades o demandas obreras con la potencia para desestabilizar la redemocratización y la prosperidad. Más que los sindicatos, esos partidos aceptaron plenamente los fundamentos del modelo económico neoliberal. Querían gobernar, no agitar. La Democracia Cristiana expuso ideas muy moderadas. Los socialistas tomarón posiciones dramáticamente más pragmáticas y centristas que en la época de Allende. Y fuera de la Concertación, los comunistas poseían mucho menos influencia que antes.

En vísperas del plebiscito, los sindicatos eligieron a los directores de la CUT: 64 \% pertenecía a los partidos de izquierda, principalmente Comunista y Socialista, $36 \%$ a la Democracia Cristiana. Este resultado demostró mucha lealtad a estos partidos a través de los años dictatoriales, con un crecimiento impresionante del PDC. En una encuesta a los trabajadores en Santiago en 1988, el líder sindical más respetado fue el demócrata cristiano Manuel Bustos de la CUT, con el apoyo del $35 \%$, seguido por un 49 \% que se declaró sin opinión. En 1971, la CUT había eligido al $71 \%$ de los directores de la izquierda, $26 \%$ del PDC. En 1991, triunfó el $54 \%$ de la izquierda (34 \% socialista, $20 \%$ comunista) y un $45 \%$ del PDC. Aunque todavía liderada por esos partidos políticos, la nueva CUT adoptó una postura ligeramente más independiente de los partidos en contraste con la situación bajo la UP.

Con la ascensión de los sindicalistas demócrata cristianos, la renovación de los socialistas y la reducción de los comunistas, la CUT emitió pronunciamientos políticos más reformistas ahora. En vez de la lucha de clases, se enfatizó la recuperación de la democracia, la defensa de los derechos humanos y la reforma del código laboral. Para el sindicalismo, el enemigo principal ahora fue definido como el autoritarismo, no el capitalismo. La gran mayoría de los sindicatos apoyó a los partidos de la Concertación en las victorias del plebiscito de 1988 y de las elecciones presidenciales del demócrata cristiano Patricio Aylwin (1990-94) en 1989, del también DC Eduardo Frei (1994-2000) en 1993, y del socialista Ricardo Lagos (2000-2006) en 1999/2000.

\section{DESPUÉS DEL GOBIERNO MILITAR}

Durante los gobiernos de la Concertación, el nuevo modelo chileno fue una combinación de una economía neoliberal protegida de las intervenciones extensas del Estado con una democracia liberal resguardada de la voluntad plena de los ciudadanos. En 1990, esta coalición tomó el poder dominada por los demócrata cristianos y los socialistas, ambos grupos amigos del movimiento obrero. El otro grupo político importante aliado con los sindicatos, los comunistas, quedó fuera de la alianza gubernamental y el Congreso. En contraste con la redemocratización en Brasil, Argentina y Uruguay, el primer gobierno después de la transición en Chile representó a los sindicatos y a sus aspiraciones. Y prometió, no solamente la democratización, sino también las reformas socia- 
les y laborales. Encuestas realizadas en 1990 y después, revelaron que la gran mayoría de los chilenos estaban en favor de reformar la legislación laboral para elevar la posición de los sindicatos. Dada la combinación política y la prosperidad económica, el triunfo de la Concertación parecía como una coyuntura excepcionalmente positiva para los trabajadores ${ }^{4}$.

Bajo el neoliberalismo continuado de la Concertación, los trabajadores participaron de un "milagro económico" que superó los acontecimientos ocurridos durante la dictadura. De 1990 a 1996, la economía creció un promedio anual encima del 7 \%. El gobierno redujo el desempleo y la inflación a un 6 \% (aunque la cesantía llegó al 9 \% en el 2003). Mejoró la educación, la salud y la expectativa de vida. Los gastos públicos sociales por habitante se expandieron en más de un 7 \% por año, no obstante que la red de seguridad social seguió siendo insuficiente. En la primera mitad de la década, la población en pobreza cayó desde un $39 \%$ hasta un $23 \%$ y la que se encontraba en indigencia bajo desde un $13 \%$ hasta un $6 \%$. La productividad del trabajo se incrementó en un promedio anual de $4 \%$, el empleo $3 \%$ y los salarios reales $5 \%$.

A pesar de estos logros grandes, la distribución del ingreso no mejoró y fue la más desigual en la América Latina después de Brasil. Para 1996, el ingreso promedio del quintil superior de ingresos fue casi 14 veces mayor al ingreso promedio del quintil inferior de ingresos. Dentro del modelo neoliberal, el gobierno no pudo hacer mucho para mejorar la distribución desigual del ingreso, salvo la promoción de la educación. Al mismo tiempo, muchos trabajadores sufrieron de puestos precarios, malas condiciones de trabajo, sindicatos impotentes, y servicios sociales inadecuados. Algunos trabajadores se encontraron con cambios difíciles en su lugar de trabajo, como la flexibilización, la fragmentación, la inseguridad del empleo, el trabajo temporal, las subcontrataciones, las horas largas, y la mecanización. Ahora el problema máximo no fue el empleo, sino la calidad de éste. Por eso, una encuesta en 1998 mostró que un 53 \% de la población tenía la opinión que la economía había mejorado en la democracia, pero un 83 \% tuvo la certeza que sus propias vidas no habían mejorado.

Muchas mujeres trabajaban en condiciones malas, sin embargo, otras no podían encontrar empleo alguno. En los noventa, la participación femenina urbana en la fuerza de trabajo fue solamente del 37 \%, más baja que en Argentina, Brasil o México. En 1998, las mujeres ganaron un promedio de 25 menos que los hombres, y sólo Brasil tuvo una discriminación salarial femenina peor en la América Latina. Solamente 21 de de los sindicalistas chilenos eran mujeres ${ }^{5}$.

Por razón de todos estos problemas económicos-sociales, los sindicatos enfrentaron obstáculos para organizar a los trabajadores. Otros desafíos estructurales fueron el crecimiento del trabajo descentralizado, del individual, del a domicilio, del en empresas pequeñas, del trabajo femenino, y del trabajo en servicios. Al mismo tiempo, los líderes sindicales encontraron una cultura trabajadora más dedicada al individualismo y al consumismo por sobre las identificaciones colectivas y políticas. Muchos sindicalistas lamentaron la evaporización de los valores de solidaridad de clase. Y los sindicatos no tenían mucho éxito en la lucha contra estas dificultades, aunque el contexto económico de alto crecimiento y el empleo ofreció oportunidades teóricas para la presión sindical.

$4 \quad$ Para la evolución bajo la Concertación, algunos libros informativos son Cortázar (1993); Morris (1998); Drake y Jaksic (1999); Haagh (2002); y Winn (2004).

Meller (1999), pp. 60-61. 
A fines de los noventa, y al amanecer del nuevo siglo, el descontento latinoamericano con el neoliberalismo se desplegó después de la recesión económica, pero no se manifestó mucha resistencia al modelo en Chile. En vez de cuestionar la receta neoliberal, el gobierno de Lagos confirmó su adhesión al sistema. Agregó promesas de ajustarlo para prestar más atención a la pobreza, la desigualdad y el deterioro medioambiental. Sobre todo, Lagos persiguió acuerdos de libre comercio exterior, especialmente con los Estados Unidos. Es posible que esta intensificación de la globalización en Chile pueda ayudar a la economía y a muchos trabajadores, pero es dudoso que ella vaya a ampliar el rol de los sindicatos.

Si bien muchos trabajadores se beneficiaron del contexto económico general en esa década, no recibieron tratamiento especial de la Concertación. Tampoco recibieron muchas mejoras en la legislación laboral. No obstante algunas modificaciones útiles, la lógica férrea del sistema de relaciones laborales no se rompió desde 1979 hasta el 2003. Dado el plan de la economía, la debilidad del sindicalismo, la intransigencia de la derecha y la cautela de la Concertación, no pasaron reformas rotundas. La derecha económica y política defendió las reglas laborales que favorecen a los empresarios, una demostración del poder gigantesco de los capitalistas dentro del modelo económico impuesto por Pinochet y el poder exagerado de los partidos conservadores dentro del modelo político impuesto por éste. Al mismo tiempo, la Concertación aceptó el concepto de la necesidad de la flexibilidad del mercado laboral sin mucha intervención del Estado en las relaciones entre trabajadores y empresarios. En el fondo, no quería molestar la propiedad privada. Para sostener el modelo económico, la Concertación tuvo que prestar más atención a la satisfacción de los empresarios en vez de los trabajadores. Frente a la presencia lejana del Estado y la hostilidad de los empleadores, los trabajadores necesitaron sindicatos fuertes para aprovecharse de las oportunidades en el mercado.

Aylwin aumentó el salario mínimo y fortaleció un poco la seguridad del trabajo, la capacidad sindical de organizarse y el sistema de negociaciones colectivas. Sin embargo, los hombres de negocio mantuvieron su superioridad sobre los sindicatos, los trabajadores, sus derechos, sus demandas y sus ingresos, especialmente en las pequeñas empresas. Los esfuerzos nacionales para construir una concertación social sobre la política económica entre el gobierno, los sindicatos y los capitalistas tuvieron algunos éxitos preliminares, pero no duraron ni lograron mucho, básicamente, por razón de la resistencia del empresariado.

Como la experiencia de otros trabajadores con los gobiernos de sus colaboradores políticos en el periodo después de las transiciones en España (con los socialistas) y en Argentina (con los peronistas), cuando esos partidos adoptaron el modelo neoliberal, los sindicalistas chilenos quedaron desilusionados y maltratados, pero sin otras opciones. Para ellos, su situación llegó a ser mucho más favorable después de la salida de la dictadura, pero menos favorable que la situación esperada. Mientras tanto, la Concertación exigió a los sindicalistas suprimir sus demandas para evitar la inestabilidad. Así, su relación con los sindicatos ayudó al gobierno a mantener el crecimiento económico sin inflación y sin grandes conflictos sociales.

Pese al mantenimiento de la mayoría de las restricciones legales, el movimiento obrero mejoró su situación en los primeros años de la nueva democracia, aunque retrocedió después. El número de sindicatos y de sus afiliados continuaron el crecimiento que comenzó tras la depresión de 198285. En los noventa, el número de sindicatos se incrementó, pero su tamaño promedio descendió. 
El porcentaje de sindicalización de la población económicamente activa subió desde un 14 \% en 1986 a un $22 \%$ en 1991, declinando posteriormente a un 16 \% en 1997 (en comparación con el $19 \%$ en toda la América Latina) y a un $10 \%$ en el 2000 . También el receso sindical disminuyó y después se recuperó. Al mismo tiempo, las huelgas y las negociaciones colectivas se multiplicaron, particularmente con demandas para salarios mejores. En el mismo rumbo que los otros indicadores, el número de huelgas surgió desde 1987 hasta 1993 y después bajó. El porcentaje de la fuerza laboral cubierto por negociaciones colectivas subió de $9 \%$ en 1986 a 14 \% en 1991, colapsando a $11 \%$ en 1996 y a $3 \%$ en el 2000 . A pesar de unas ganancias, los sindicatos bajo la Concertación lograron ser sólo un pálido reflejo de su historia pre-golpe ${ }^{6}$.

Durante la presidencia de Eduardo Frei Ruiz-Tagle no ocurrieron cambios significativos ni en la legislación laboral ni en la ausencia de apoyo gubernamental a los sindicatos en disputas con los propietarios. Por eso, el grado de conflicto laboral continuó bajo. Aceptando el liderazgo de una coalición política que no respondió a muchas demandas obreras, los líderes oficiales de los sindicatos enajenaron a algunos trabajadores. Cuando los trabajadores salieron del sindicato, algunos trataron de crear alternativas más independientes y militantes. La CUT perdió miembros e influencia durante la segunda mitad de la década. También sufrió divisiones políticas internas, particularmente entre los comunistas y los socialistas, y, especialmente, sobre la cuestión de la confrontación o colaboración con el gobierno.

Por fin en el 2001, Lagos consiguió una reforma parcial, pero importante, en las normas laborales. Mejoró la seguridad del trabajo, las condiciones laborales, las horas de trabajo, los beneficios para el desempleo, los derechos de trabajadores temporales y la capacidad para sindicatos de organizarse y de participar en negociaciones colectivas. Aunque la derecha denunció la reforma, la balanza desigual en favor de los empresarios sobre los trabajadores continuó, como dijo la CUT en voz alta, encabezada por el socialista Arturo Martínez. Repetidamente, la CUT criticó también el tamaño del salario mínimo, pero el gobierno respondió que un salario más alto podría agravar el desempleo (alrededor de $9 \%$ ).

Aunque insatisfechos con sus compensaciones bajo la Concertación, los sindicatos generalmente mantuvieron su apoyo electoral a la coalición. Con la polarización entre el gobierno y los expartidarios de la dictadura, los sindicalistas no tuvieron otra opción política viable. Sin embargo, poco a poco algunos trabajadores se abstuvieron de sufragar o votaron por los comunistas 0 , aun, por los candidatos derechistas.

\section{CONCLUSIONES}

Como el ejemplo más elogiado del neoliberalismo en la América Latina, Chile puede ser la prueba de los resultados para la clase obrera. Después de la represión de Pinochet, los trabajadores obtuvieron mucho de la Concertación, particularmente con la modificación del modelo económico para mejorar la vida de los pobres, con la reforma parcial de las regulaciones laborales y con la liberación y la toma de poder de sus partidos políticos.

Los datos sobre sindicalización varían de unas fuentes a otras, pero todas están de acuerdo sobre un auge al comienzo del régimen de la Concertación y una caída después. 
En los noventa, sin embargo, el movimiento obrero no encontró una estrategia alternativa al desarrollo para combatir el modelo neoliberal de modernización. Aunque muchos trabajadores ganaron individualmente durante la prosperidad de esa década, los sindicatos no conquistaron mucho poder. Esas organizaciones no tuvieron gran palanca ni con los dueños de la propiedad (más fuertes que hace treinta años) ni con el Estado (más reducido que hace tres dácadas). Algunos trabajadores aceptaron su rol inferior en el nuevo sistema económico a cambio de crecimiento rápido, tasas altas de empleo, estabilidad prolongada, inflación baja, salarios viables y oportunidades para consumo. Hasta cierto punto, evolucionó un nuevo contrato social implícito entre la burguesía y el proletariado, parecido a ciertos arreglos amplios, tácitos y desiguales en Europa y Estados Unidos.

En muchos aspectos, la experiencia del movimiento obrero chileno con la salida del autoritarismo capitalista fue similar a la de sus contrapartes en los otros países del Cono Sur. La moderación de los sindicatos y sus aliados en los partidos políticos ayudó a la establidad de la redemocratización, pero disminuyó la posibilidad de reformas laborales sobresalientes. Con el renacimiento de la democracia, los sindicalistas recapturaron su capacidad de participar, organizar y negociar libremente, aunque dentro de los límites de una economía dedicada al mercado y un sistema político dedicado a la estabilidad. Los trabajadores restringieron sus actividades durante y después de la transición democrática por cuatro razones: (1) su temor tras los años de terrorismo del Estado; (2) su debilidad económica; (3) su fragilidad institucional; y (4) la moderación de la posición ideológica de sus sindicatos y sus partidos políticos. Los últimos tres factores reflejaron no solamente la trayectoria chilena, sino también la tendencia internacional en los ochenta y los noventa, con las ondas de fracaso del sindicalismo, populismo, socialismo y la izquierda tradicional y del triunfo del neoliberalismo económico y político.

Desde un punto de vista, Pinochet tuvo éxito en su determinación de eliminar cualquier alternativa al capitalismo del mercado y cualquier posibilidad de un proyecto socialista de los trabajadores y sus partidarios izquierdistas. Obviamente, el golpe y el régimen militar intensificaron y aceleraron estos cambios económicos, sociales e ideológicos -especialmente la erosión del sindicalismo y socialismo-, aunque no rompieron la alianza histórica entre los sindicatos y sus partidos. Sin embargo, tal vez estas transformaciones no requerían ni el golpe ni la brutalidad y la duración de la dictadura chilena, porque la misma cosa ocurrió pacíficamente en muchos otros países, aun en aquellos con movimientos izquierdistas o laboristas fuertes, como España, Portugal, Italia, Francia e Inglaterra. La disminución del sindicalismo y su poder político no fue solamente un fenómeno chileno, sino una tendencia mundial, una función de los cambios económicos e ideológicos globales de los ochenta y los noventa, por ejemplo, el triunfo del neoliberalismo y el fin de la Guerra Fría. Con la perspectiva histórica de treinta años, quizás el factor más importante en esta nueva dirección sindical fue la reorientación económica, no la represión.

En el largo plazo, ¿fue necesario el golpe de 1973 para conseguir estas tranformaciones en Chile? ¿Fue necesario el golpe para producir el Chile de hoy? ¿Sin el Golpe, habría sido posible que otros mecanismos produjesen resultados similares después de treinta años? Es imposible saber, pero es interesante especular.

A la luz de la propensión general, en la América Latina desde 1980 hasta hoy día, la hegemonía del modelo neoliberal y la subordinación del movimiento obrero y de la izquierda parecen posibles en 
Chile en el 2003 sin el golpe 0, por lo menos, sin una dictadura tan violenta y tan larga. Para un historiador, la respuesta a esta pregunta hipotética depende en parte de la interpretación de la fuerza, la potencia y las intenciones de la Unidad Popular y de la movilización desde abajo de los trabajadores en 1973. ¿Fue indispensable la intervención masiva militar para bloquear la vía chilena hacia el socialismo? ¿no existían otros métodos?. Aun si el golpe fue necesario para cambiar la situación en 1973, ¿fue necesario para producir la realidad opuesta del 2003 ? ¿fue necesaria tanta violencia para crear una economía neoliberal, cuando no lo fue para hacer la misma cosa en países como Argentina, Bolivia, Perú y México? En contraste con Chile, muchos otros países han tenido reformas parecidas sin miles de muertos. A pesar de unas historias nacionales y unos regímenes políticos muy distintos, muchos movimientos obreros en muchos otros países han llegados a posiciones muy débiles y moderadas en la actualidad.

A mi juicio, es posible imaginar la evolución de los sistemas económicos, sociales y políticos de Chile hasta la situación actual sin el golpe, en conformidad con las normas internacionales. Pero, no es mi conclusión para ahora. Sin tomar una posición definitiva, solamente quiero introducir esta cuestión en el debate para evaluar las causas principales de los resultados de los últimos treinta años en una perspectiva comparativa e internacional. Por ejemplo, si el golpe no fue necesario para realizar los logros celebrados por sus defensores, tal vez su única contribución fue la destrucción de la democracia y los derechos humanos.

En este nuevo siglo, la solidez del contexto liberal económico, institucional y político -tanto internacional como doméstico- indica la continuidad del rol modesto del movimiento obrero. Por lo menos, el futuro del sindicalismo no parece auspicioso. En este momento de globalización, el dominio mundial de los Estados Unidos, del modelo económico neoliberal, de los capitalistas móviles y de la democracia neoliberal parece firme, a pesar del descontento creciente en muchos países. Dentro de este marco liberal, Chile es el caso más exitoso y famoso en América Latina. Aunque tiene problemas serios, son pequeños en comparación con sus vecinos. Debido a su inmersión profunda en el régimen global del liberalismo, los logros y la estabilidad de su actual sistema económico y político, y la balanza de fuerzas entre los concertacionistas y la derecha, los cambios fundamentales en la trayectoria esencial de Chile parecen improbables. Sin algunas transformaciones masivas en estos factores, el resurgimiento pronto del movimiento de los trabajadores sería una sorpresa. Quizás la situación chilena está llegando a ser típica de la modernización neoliberal en este momento histórico del mundo occidental.

\section{REFERENCIAS}

Angell, Alan. 1972. Politics and the Labour Movement in Chile. London: Oxford University Press. Barrera, Manuel et al. 1985. Sindicatos y Estado en el Chile actual. Santiago: Centro de Estudios Sociales.

Barrera, Manuel y Gonzalo Falabella. 1990. Sindicatos bajo regímenes militares: Argentina, Brasil, Chile. Santiago: Centro de Estudios Sociales.

Bitar, Sergio, y Crisóstomo Pizarro. 1986. La caida de Allende y la huelga de El Teniente. Santiago: Ediciones del Ornitorrinco. Campero, Guillermo y José A. Valenzuela. 1981. El movimiento sindical chileno en el capitalismo autoritario (1973-1981). Santiago: Instituto Latinoamericano de Estudios Transnacionales.

Constable, Pamela y Arturo Valenzuela. 1991. A Nation of Enemies: Chile under Pinochet. New York: W. W. Norton. 
Cortázar, René. 1993. Politica laboral en el Chile democrático: Avances y desafíos en los noventa. Santiago: Ediciones Dolmen.

Drake, Paul W. 1992. Socialismo y populismo. Chile, 1936-1973. Valparaíso: Instituto de Historia.

Drake, Paul W. 1996. Labor Movements and Dictatorships: The Southern Cone in Comparative Perspective. Baltimore: J ohns Hopkins University Press.

Drake, Paul W., e Iván Jaksic. 1991. The Struggle for Democracy in Chile, 1982-90. Lincoln: University of Nebraska Press. Drake, Paul W., e Iván Jaksic. 1999. El modelo chileno: Democracia y desarrollo en los noventa. Santiago: LOM.

Epstein, Edward C. 1989. Labor Autonomy and the State in Latin America. Winchester: Unwin Hyman.

Frías, Patricio. 1989. El movimiento sindical chileno en la lucha por la democracia, 1973-1988. Santiago: Alborada.

Gallitelli, Bernardo y Andrés A. Thompson. 1982. Sindicalismo y regímenes militares en Argentina y Chile. Amsterdam: CEDLA. Garretón, Manuel Antonio. 1984. Dictaduras y democratización. Santiago: FLACSO.

Garretón, Manuel Antonio. 1995. Hacia una nueva era política: Estudio sobre las democratizaciones. México: Fondo de Cultura Económica.

Haagh, Louise. 2002. Citizenship, Labour Markets, and Democratization: Chile and the Modern Sequence. New York: Palgrave. Meller, Patricio. 1999. "Pobreza y distribución del ingreso en Chile (Década de los noventa)". En Drake y Jaksic, 39-64.

Menéndez Carrión, Amparo y Alfredo Joignant. 1999. La caja de Pandora: El retorno de la transición chilena. Santiago: Planeta.

Morris, Pablo. 1998. Sindicatos en receso: La otra cara de la estabilidad sindical. Santiago: Dirección del Trabajo, Departamento de Estudios.

Moulian, Tomás. 1997. Chile actual: Anatomía de un mito. Santiago: LOM-ARCIS.

Piñera, José. 1990. La revolución laboral en Chile. Santiago: Zig-Zag.

PNUD. 1998. Desarrollo humano en Chile 1998. Las paradojas de la modernización. Santiago: PNUD.

Ruiz-Tagle, Jaime. 1985. El sindicalismo chileno después del plan laboral. Santiago: Programa en Economia y Trabajo.

Sigmund, Paul E. 1977. The Overthrow of Allende and the Politics of Chile, 1964-1976. Pittsburgh: University of Pittsburgh Press.

Silva, Eduardo. 1996. The State and Capital in Chile: Business Elites, Technocrats, and Market Economics. Boulder: Westview Press.

Toloza, Cristián, y Eugenio Lahera. 1998. Chile en los noventa. Santiago: Ediciones Dolmen.

Valenzuela, J. Samuel y Arturo Valenzuela. 1986. Military Rule in Chile: Dictatorship and Oppositions. Baltimore: J ohns Hopkins University Press.

Winn, Peter. 1986. Weavers of Revolution: The Yarur Workers and Chile's Road to Socialism. New York: Oxford University Press.

Winn, Peter. 2004. Victims of the Chilean Miracle. Durham: Duke University Press.

Paul W. Drake es profesor del Instituto de las Américas del Centro de Asuntos Interamericanos de la Universidad de California, San Diego. Ocupa cargos en los Departamento de Ciencia Política, Historia y en la Escuela de Graduados de Relaciones Internacionales y Estudios del Pacífico de la misma universidad. También es el decano de Ciencias Sociales. Es ex presidente de la Asociación Latinoamericana de Estudios y ex jefe del Consejo Regional Asesor de investigación en Ciencias Sociales de América Latina. Doctor (Ph.D.) de la Universidad de Stanford, Drake ha publicado ampliamente sobre Chile, el Cono Sur, LoS Andes y las relaciones Estados Unidos - Latinoamérica. En forma individual es autor de tres libros: Socialism and Populism in Chile; The Money Doctor in the Andes; and Labor Movements and Dictatorships. (E-mail: pdrake@ucsd.edu) 